\title{
Review of on-site and communal water and sanitation systems for remote communities
}

\author{
A. Perks \& T. Johnson \\ R.V. Anderson Associates Limited, Ottawa, Canada
}

\begin{abstract}
Many small communities across Canada rely on on-site or communal water and wastewater systems to meet their needs, and several factors are likely to reinforce this direction: a) the reduction in grants available from senior levels of government to assist small communities with capital upgrades; b) the emergence of new small scale technologies for water and wastewater treatment that can be cost-effectively applied at the small community level, reducing the need for costly underground piping networks; and c) regulatory pressures to adopt full cost pricing that will force small communities to seek lower cost solutions.

Servicing costs for small communities may be significantly reduced and still provide acceptable and comparable levels of service, as well as employment opportunities within the communities. Because many significant problems and / or failures in on-site and communal water systems have been attributed to inadequate O\&M, it is unlikely that more complex technologies requiring higher levels of expertise will represent a sustainable solution. On-site and communal systems may be a more sustainable solution for smaller communities, perhaps using contract O\&M services, and should be carefully considered.
\end{abstract}

Keywords: water, wastewater, onsite, policy, community servicing.

\section{Introduction}

Throughout Canada, small communities are typically served by on-site or communal water and wastewater systems where it is impractical to construct a centralized system due to the high cost and/or low density of population. According to Environment Canada's MUD survey in 2001, more than three million rural homes and buildings are not connected to municipal systems. Dalhousie University has reported that more than $50 \%$ of the population of 
Nova Scotia depend upon on-site sewage systems, principally septic tanks and leaching beds.

Within the National Capital Region itself, there are 26 villages within the newly amalgamated City of Ottawa that still rely upon on-site or communal facilities to meet their needs; again, mostly private wells and septic systems. At a recent workshop for rural residents held by the City of Ottawa in March 2007, these rural and village residents expressed satisfaction with their services, and rural homeowner groups such as the Carleton Landowner's Association clearly advocated for decentralized water and sewage systems for village scale communities.

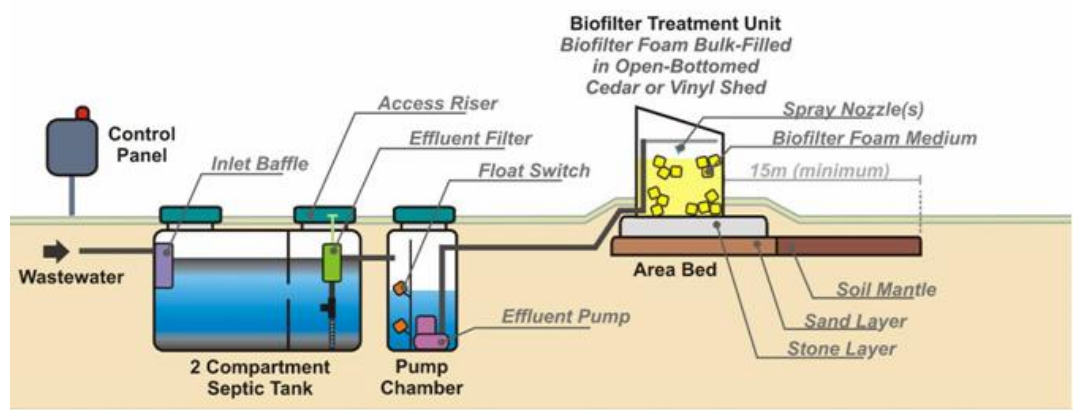

Figure 1: Modern septic system.

Conservation Authorities established on a watershed basis are also playing an important role. The South Nation Conservation, for example, monitors water quality and the operation and maintenance of on-site and communal systems within the watershed - 72 small communities ranging in size from a few houses to small villages of a hundred or more houses. South Nation Conservation provides all inspections of homes or businesses that construct private services. This centralized service ensures consistent standards, and a watershed approach to managing wastewater. Fees are charged for inspections under this program.

\section{Managing small community infrastructure}

\subsection{Servicing strategies}

Small and remote communities are often characterized by low growth rates and a need for a complete community water and wastewater servicing solution (compared to a development phased approach). The different infrastructure servicing arrangements can be categorized as follows:

- Category I - On-site wells and septic tanks owned and operated by the residents;

- Category II - Cluster or decentralized public systems (public or private); and

- Category III - Centralized public systems involving complete piped networks. 
The simplest technology that meets the appropriate operational standards will usually result in the lowest life cycle costs. Illustrated below is a home scale water treatment unit.

New technologies are now available to enhance the performance of on-site systems, such as filters and aerobic units installed between the septic tank and the leaching bed to prevent bed failure, to remove BOD, suspended solids, nitrates and phosphates, to disinfect effluents, and to accommodate more difficult soils and topography. The next level of treatment devices, including Biological Contactors and Aerobic Treatment package plants are available to handle small communities and clusters of homes. The Canadian Water and Wastewater Association recently prepared a summary of current technologies related to small scale water and wastewater treatment, including equipment for adsorptive media, filtration, disinfection, nutrient removal, and reverse osmosis.

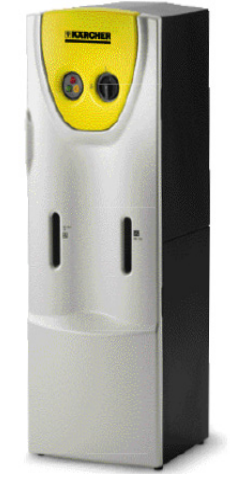

Figure 2: Home water treatment system.

\subsection{Asset management}

The capital cost of central water supply and wastewater infrastructure in urban areas is typically in the range of $\$ 25,000$ per house, including treatment plants and piped sewage collection/water distribution infrastructure. These urban systems are provided in urban areas where the lot sizes are relatively small (i.e. $15-20 \mathrm{~m}$ widths). Larger rural lot communities are usually serviced by means of private wells and septic systems due to the high cost of the underground water and sewer networks. A simple asset management model for an urban system, broken down into operational cost components, shows how a typical capital investment of $\$ 25,000$ per connection would break down.

Assuming a water consumption of $375 \mathrm{l} / \mathrm{c} / \mathrm{d}$, then these costs would be reflected in a water rate of about $\$ 3.88$ per $^{3}$ of water consumed.

Not many Canadian municipalities are in fact spending $\$ 2,125$ per connection per annum at present. Discounting the system renewal and debt repayment costs above brings the annual O\&M cost to about $\$ 1,250$ per annum, not far off a typical homeowners water and sewer bill in most municipalities. 
Table 1: $\quad$ Asset management model.

\begin{tabular}{|l|r|}
\hline Capital asset value (CAV) per person & $\$ 25,000$ \\
\hline Annual O\&M cost @ 5\% of CAV & $\$ 1,250$ \\
\hline Treatment and purification cost @ 30\% O\&M & $\$ 375$ \\
\hline Distribution and collection cost @ 30\% of O\&M & $\$ 375$ \\
\hline General and administrative costs @ 40\% of O\&M & $\$ 500$ \\
\hline Renewal of short life assets @ 2\% of CAV per annum & $\$ 500$ \\
\hline Debt repayment @ 30\% of annual O\&M Cost (maximum) & $\$ 375$ \\
\hline Total annual operating cost & $\begin{array}{r}\$ 2,125 \\
\text { or } 8.5 \% \text { of CAV }\end{array}$ \\
\hline
\end{tabular}

Much of Canada's water and sewage infrastructure was financed with the assistance of Federal and Provincial grants to assist municipalities with capital upgrades, and as a result many smaller communities have centralized systems offering a high level of service in terms of flows, pressures and capacities. But over the last decade or so, these capital grants have been significantly reduced through a process of downloading and cost cutting. The result has been the emergence of an "infrastructure deficit" - slowly deteriorating assets that are beginning to wear out and break down. Smaller, more remote communities are particularly vulnerable, and are seeking lower cost systems, easier to operate and maintain in the long term.

\subsection{System performance}

Anticipated cost increases could be at least partially offset by reducing financial losses associated with unaccounted for water and inflow/infiltration. For example, water production and billing records for small communities often indicate a high unaccounted for water rates (30-40\%), well beyond acceptable standards for small municipalities $(15 \%)$. On the other hand, the extra inflow and infiltration entering through leaks and cross-connections and must be treated at the wastewater treatment plant, needlessly reducing the communities ability to handle new development. Both of these represent significant lost revenue and additional operational costs to small communities - as much as $25 \%$ of their annual operating budget. Therefore aggressively working to eliminate these losses would help offset rate increases over the next few years.

The development of simple performance indicators or benchmarks could be used to assess the performance of on-site and communal services, such as:

- Percentage of well water tests that comply with standards;

- Percentage of septic tank systems that are inspected each year;

- Percentage of lagoon capacity remaining;

- Percentage of failed leachate beds in the community; and

- Percentage of unplanned service interruptions. 
Operators of small systems can establish target values for the performance indicators and determine the system's performance over time, thereby anticipating problems and identifying corrective actions.

\section{Operations and maintenance costs}

\subsection{Water supply}

The Ontario Water Works Association used to survey water rates and operations and publish an annual report, but the last one was in 1999, and indicated an annual O\&M cost of $\$ 412$ per connection for water supply for communities with less than 1,000 accounts. This represents about $\$ 500$ per account in 2007 dollars, or approximately $\$ .91$ per $\mathrm{m}^{3}$ ( $\$ 910$ per ML) of water used, assuming $550 \mathrm{~m}^{3}$ per year per account.

The Canadian Water and Wastewater Association recently contacted a number of municipalities and agencies to gather data and information on small water and sewage system costs.

The CWWA found that many small communities across Canada still rely on on-site water and sewage systems. The costs of operating these systems varies widely, but on average the operators reported spending about $\$ 444$ per connection per year on water systems, and $\$ 313$ per connection per year on wastewater. Assuming a water use of $240 \mathrm{~m}^{3}$ for a typical household (ie connection), this translates into $\$ 1.85 \mathrm{per}^{3}$ ( $\left.\$ 1850 / \mathrm{ML}\right)$ for water and $\$ 1.30$ per $\mathrm{m}^{3}(\$ 1304 / \mathrm{ML})$ for wastewater.

In Nova Scotia, the Halifax Regional Water Commission operates a number of small water systems. Operational costs for some of their small systems range from about $\$ 800$ per ML for a system with 350 customers, to $\$ 14.40$ per $\mathrm{m}^{3}$ $(\$ 14,400$ per ML) for a system serving only 11 customers. The high costs also reflect specific water quality issues to be addressed.

The Ontario Ministry of Municipal Affairs and Housing operates the Municipal Performance Measurement Program (MPMP), which surveys large and small municipalities regarding their operating costs. The most recent compilation for 2003 indicates that for municipal water supply systems serving less than 5,000 persons, operations costs of water produced were $\$ 1.03$ per $\mathrm{m}^{3}$ (\$1028 per ML - see Figure 3).

The economies of scale are also evident from this figure, as larger municipalities (greater than 40,000 in population) report operating costs as low as $\$ .39$ per $^{3}$ ( $\$ 386$ per ML), whereas for smaller communities the unit cost of producing drinking water is much higher.

It is clear that many factors affect the cost of providing drinking water. Chief among these would be the raw water quality and what has to be done to bring the water to an acceptable level of finished water quality. Another important element is the topography; systems able to make use of gravity to supply and distribute water have a natural economic advantage over those that have to pump and repump water significant distances and elevations. 
The age and condition of the facilities is also an important determinant of production cost - for example unplanned maintenance on an emergency breakdown basis may increase the operating costs significantly - by as much as 15 times if a major component breaks down and damages other parts of the system.

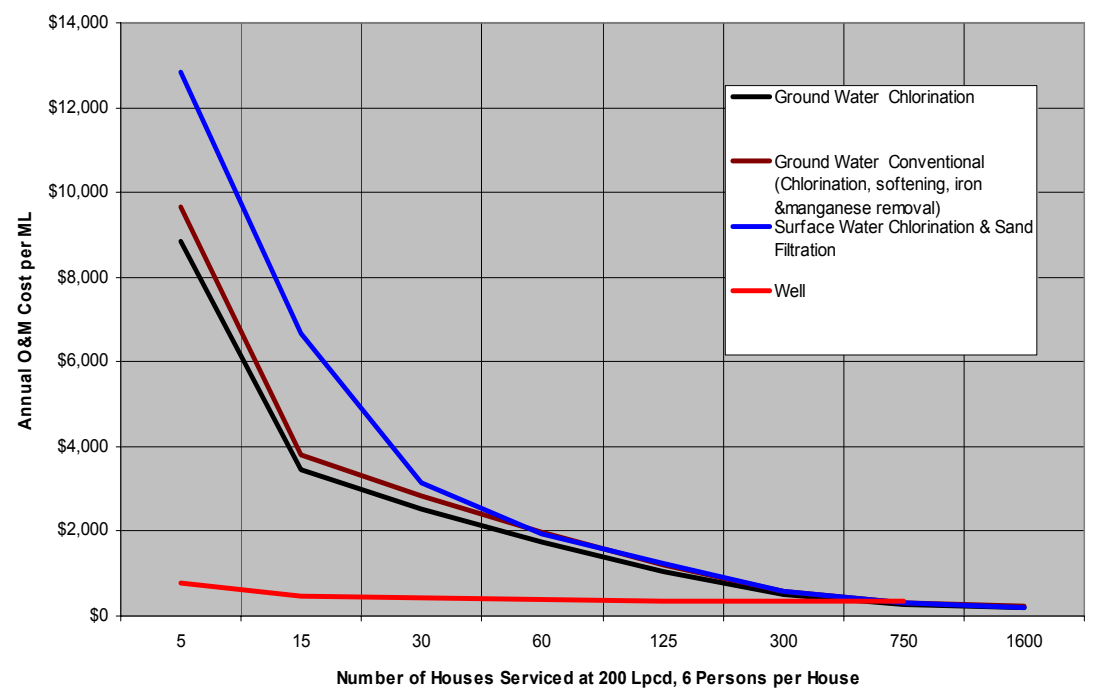

Figure 3: Annual O\&M cost for megalitre - water treatment.

Given that up to $85 \%$ of the cost of a water system can be represented by the distribution piping, ongoing deterioration and replacement costs can drive the cost of supplying water up to unaffordable levels.

Cost factors may be even more unpredictable for remote communities of several hundred people or less. The cost models currently in use by Indian and Northern Affairs Canada for remote communities indicate that supplying small remote communities can be as much as $40-50$ times the cost of operating piped systems for larger urban communities in the 5,000-10,000 population range.

Typically though, an on-site drinking water system comprising a well, appropriate filters (for solids removal) and UV or ozonation disinfection will cost to the order of $\$ 300 /$ year for filter replacement and energy consumption. Added point-of-entry systems can be applied for softening, iron or manganese removal and even uranium removal where necessary. These costs can be reduced if dual water systems are built into the houses for non-potable water uses (such as toilet flushing) using untreated water. The Canadian War Museum in Ottawa uses untreated river water for toilet flushing purposes, and city water for all other purposes. 


\subsection{Wastewater treatment}

A similar pattern emerges for wastewater collection and treatment. The operational cost reported in the Ontario MPMP database for communities with a population of less than 1,000 persons is $\$ 341$ per ML treated, or $\$ 0.34$ per $\mathrm{m}^{3}$.

The economies of scale are not as evident, as larger municipalities (greater than 40,000 in population) report operating costs of $\$ .310$ per $\mathrm{m} 3$ ( $\$ 310$ per ML). This may be due to the fact that many communities rely on simple lagoon systems for treatment that involve relatively little operational costs, even for larger entities.

As mentioned previously, excessive inflow/infiltration entering the systems through leaks and cross-connections can inflate the operations costs rapidly.

The topography is also an important element, as it is with water; systems able to make use of gravity to collect the wastewater have a natural economic advantage over those that have to pump and re-pump the sewage over significant distances and elevations.

The age and condition of the facilities is likewise an important determinant of production cost - for example, cleaning and flushing of sewers that collect grease and debris at many locations and low points are much more costly to operate and maintain.

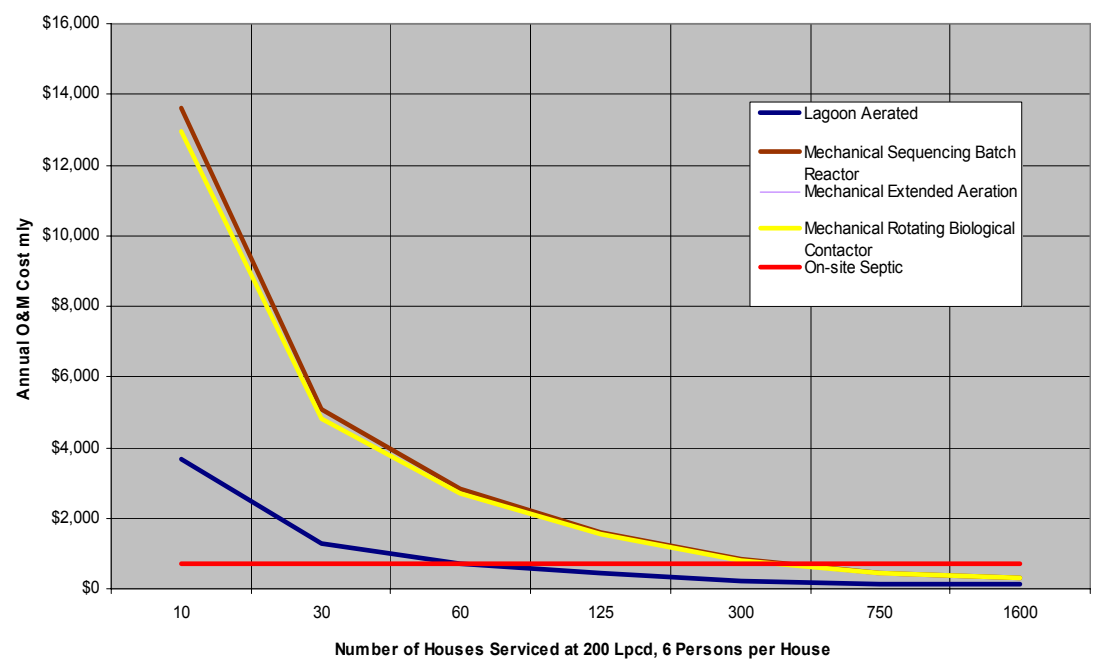

Figure 4: Annual O\&M cost comparison - wastewater.

However, perhaps the single most important factor is surface versus subsurface disposal of the effluent. If subsurface disposal can be used, such as for septic tanks, biofilters, etc, the cost is usually an order of magnitude less than the cost of surface water disposal. Therefore, wherever possible, on-site and communal systems relying on subsurface disposal should be considered for small, remote communities. 

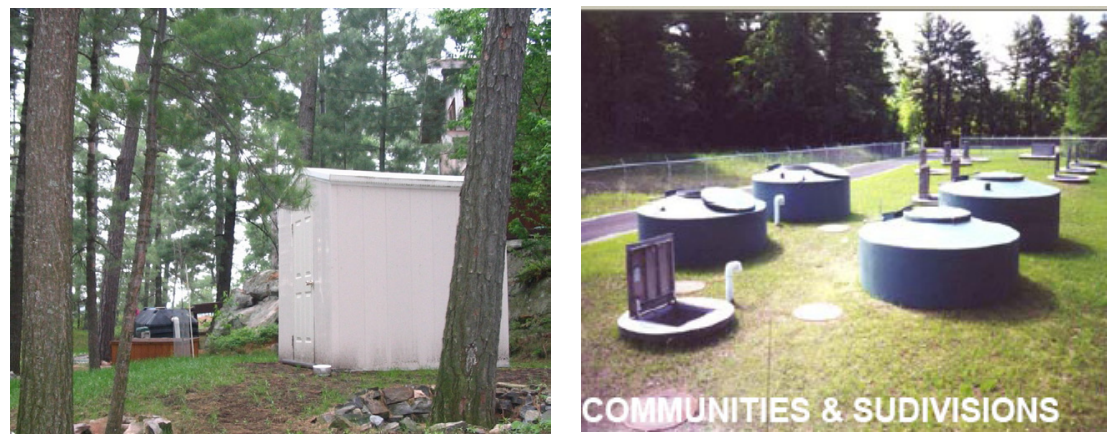

Figure 5: Typical communal wastewater systems.

\section{Summary and conclusions}

Much of rural and small town/village Canada (and the USA as well) relies upon private on-site services to meet their water and wastewater needs. Many of these residents prefer their own private, low cost systems and actively advocate against so-called "big pipe" solutions from a cost, environmental and community development perspective.

Simple and low cost technologies for on-site and communal systems can provide cost effective and environmental sound solutions on a sustainable basis. On-site and decentralized technologies appear to offer the least cost service for communities of less than 1,000 in population.

These technologies offer more effective operation of on-site water and wastewater systems, extending their useful life and enabling them to properly function in difficult soil and water quality conditions. This is important, as the cost of moving away from ground disposal of septic effluent to surface discharge, for example, is an order of magnitude higher.

The capital and operational costs of small water and wastewater networks developed in this way may be as low as $33 \%$ of the cost of more conventional piped systems.

Communal and on-site systems, such as septic systems and lagoons, require less regular maintenance than more complex electrical and mechanical treatment systems, and may be more easily monitored and serviced through regularly scheduled visits. However, past problems have often been traced to inadequate cleaning and inspection. Operational and management contracts are available to assume responsibility for the maintenance of small systems - which could be incorporated into private cluster services as well. Otherwise, regional or watershed bodies can be contracted to perform the inspection and maintenance functions for a number of communities.

A hierarchy of infrastructure strategies should be considered, beginning with on-site systems, communal and decentralized systems, and finally full piped centralized systems only where dictated by population size and density of development. Where a community is more compact in area with potential well 
contamination from septic systems, a communal water supply may offer a cost effective solution.

Further benefits may be gained by designing on-site and communal systems for wastewater recycling and reuse in which perhaps $50 \%$ of the wastewater can be recycled for use in irrigation and/or toilet flushing, for example. This further enhances the potential cost efficiency and environmental benefits for small community services. 